\title{
TERRITÓRIO, TRABALHO E SAÚDE DO TRABALHADOR: UMA APROXIMAÇÃO NECESSÁRIA
}

\author{
TERRITORY, WORK AND WORKER'S HEALTH: A NECESSARY APPROACH
}

\author{
TERRITORIO, TRABAJO Y SALUD DEL TRABAJADOR: \\ UNA APROXIMACIÓN NECESARIA
}

\author{
Guilherme Marini Perpetua - Universidade Estadual Paulista - Presidente Prudente - São Paulo - Brasil \\ geomarini@yahoo.com.br
}
Fernando Mendonça Heck - Instituto Federal de São Paulo - Tupã - São Paulo - Brasil
fernandomheck@gmail.com

\begin{abstract}
Antonio Thomaz Junior - Universidade Estadual Paulista - Presidente Prudente - São Paulo - Brasil
thomazj门@gmail.com
\end{abstract}

\section{Resumo}

Nas últimas décadas, importantes esforços de superação das trincheiras disciplinares têm sido implementados em diferentes áreas do conhecimento, como são os casos da Geografia, dos estudos do trabalho e das ciências da saúde. Nesse contexto, o presente artigo objetiva ressaltar a dimensão espacial da saúde do trabalhador, propondo uma abordagem de viés dialético-materialista centrada no conceito de território e focada para revelar traços invisibilizados da dominação e da exploração capitalista e de seu corolário, a precarização e a degradação do trabalho, em distintos lugares e setores da atividade laboral. Em termos metodológicos, recorremos, fundamentalmente, à revisão bibliográfica em diferentes fontes e áreas do conhecimento, com destaque para a Geografia e a Saúde do Trabalhador.

Palavras-chave: Território, trabalho, saúde do trabalhador, agravos do trabalho.

\section{Abstract}

In the last few decades, important over coming efforts from disciplinary trenches have been implemented in different learning areas, like the Geography cases, the labor studies and the health sciences. In this context, this paper aims to high light the space dimension of the worker's health, proposing an approach of dialecticalmaterialist bias centered in the territory concept focused in reveal unseen traits of the domination and capitalist exploration and its corollary, the precariousness and the work degradation in different places and labor activity sectors. In methodological terms, we appealed, fundamentally, to the bibliography review in different sources and areas of knowledge, featuring Geography and the worker's health.

Keywords: Territory, work, worker's health, labor injuries.

\section{Resumen}

En las últimas décadas importantes esfuerzos de superación de las trincheras disciplinarias han sido implementados en diferentes áreas de conocimiento, este es el caso de la Geografía, de los estudios del trabajo y de las ciencias de la salud. En este contexto, el presente artículo tiene por objetivo resaltar la dimensión espacial de la salud del trabajador, proponiendo un abordaje materialista-dialéctico centrado en el concepto de territorio, enfocado para dar importancia a los trazos invisibles de la dominación y la explotación capitalista y su corolario, la precarización y la degradación del trabajo en diferentes lugares y sectores de actividad laboral. 
En términos metodológicos, recurrimos fundamentalmente a la revisión bibliográfica de diferentes fuentes y áreas de conocimiento, con énfasis para la Geografía y la Salud del Trabajador.

Palabras clave: Territorio,trabajo, salud del trabajador, daños a la salud.

Introdução

Nas últimas décadas, relevantes esforços têm sido empreendidos no sentido de superação das "trincheiras" disciplinares outrora construídas sobre o alicerce positivista do paradigma fragmentário da modernidade industrial (Moreira, 2009), nas mais diversas áreas do conhecimento. Um bom exemplo deriva do cruzamento entre a Geografia, os estudos do trabalho e as ciências da saúde.

O crescimento do interesse, por parte de cientistas não geógrafos, em categorias e conceitos de cunho espacial é um fenômeno já assinalado por diversos estudiosos. ${ }^{1}$ Essa profícua aproximação não tem deixado de fora as pesquisas na área de Saúde Coletiva realizadas por médicos, sociólogos, economistas, psicólogos, entre tantos outros pesquisadores para os quais a dimensão espacial tornou-se central, ao mesmo tempo em que o campo da Geografia da Saúde consolidou-se no Brasil, na medida em que cada vez mais geógrafos também passaram a dividir com outros profissionais a preocupação com o amplo temário da saúde (Vaz; Remoaldo, 2011).

Concomitantemente, a temática do trabalho tornou-se marcante na Geografia brasileira na esteira do movimento de renovação crítica dos anos 1980, possibilitado pelo diálogo com o marxismo e a assimilação do método dialético-materialista aos estudos geográficos. Nasce daí a Geografia do Trabalho, não como mais uma nomenclatura ou subárea interna à Geografia, mas como reafirmação da centralidade ontológica e política do trabalho e, por conseguinte, categoria central para o entendimento do espaço geográfico (Thomaz Júnior, 2002). É sobre esse terreno que, nos últimos anos, cada vez mais se fortalecem investigações e abordagens voltadas para desvelar os nexos entre território e saúde do trabalhador. ${ }^{2}$ Tal interseção não deve ser vista como algo fortuito, uma vez que, longe de poder ser remetida ao passado do capitalismo, a imposição agravos à saúde dos trabalhadores segue sendo um problema atual e potencializado pelas recentes mutações no mundo do trabalho, nos contextos mundial e brasileiro. ${ }^{3}$

Motivado por este ensejo, o presente artigo objetiva ressaltar a espacialidade da saúde do trabalhador, propondo uma abordagem de 
viés dialético-materialista centrada no conceito de território, a qual, argumentamos, é capaz de revelar traços muitas vezes invisibilizados da dominação e da exploração capitalista do trabalho e de seu corolário, a precarização e a degradação do trabalho, em diferentes lugares e setores de atividade. A metodologia adotada consistiu fundamentalmente em revisão bibliográfica em diferentes fontes e áreas do conhecimento, com destaque para a Geografia e a Saúde do Trabalhador.

O texto está estruturado em três seções, além da presente introdução e das considerações finais. Na primeira, expomos brevemente o panorama atual da saúde do trabalhador no Brasil, com ênfase nas principais lacunas e problemas existentes. Na segunda, buscamos apresentar elementos para conceituar o território desde o ponto de vista do método dialéticomaterialista, visando instrumentalizar a análise posterior que, por fim, será realizada na terceira e última seção, em que delineamos nosso entendimento acerca da abordagem territorial dos agravos à saúde dos trabalhadores por meio da ideia de territórios da relação capital/trabalho.

\section{A relação trabalho-saúde no Brasil}

O reconhecimento de que a dimensão do trabalho é importante no processo saúde-doença de grande parte dos homens e mulheres ao longo do seu ciclo de vida (Silveira, 2009) não é recente, remontando aos estudos de Hipócrates (460-375 a.C) e, mais tarde, comparecendo também nas obras de Georgius Agricola (1556), Bernardino Ramazzini (1700), Karl Marx e Friedrich Engels (Agostini, 2002; Lourenço, 2008). Entretanto, se tal consideração remonta à Idade Antiga, quando se trata de ponderar o protagonismo da classe trabalhadora enquanto sujeito ativo da construção de uma política de saúde, os esforços são muito mais recentes.

Segundo Lacaz (2007), é a partir da consideração da determinação social do processo saúde-doença, oriunda da Medicina Social LatinoAmericana, da vertente programática da Saúde Pública e da abordagem em Saúde Coletiva sobre o sofrer, adoecer e morrer das classes e grupos sociais inseridos em processos produtivos, que surge a intenção real em construir um campo de práticas e conhecimentos em Saúde do Trabalhador. Sua emergência ocorre em virtude da necessidade de superar a tradicional Saúde Ocupacional centrada na história natural da doença, nos preceitos da epidemiologia clássica e nas práticas e conhecimentos da clínica, em 
que as dimensões social, histórica, política e econômica são negligenciadas na análise da exposição aos riscos, dos acidentes e das doenças do trabalho. Em termos históricos, o campo estrutura-se a partir do final dos anos 1960 e início dos anos 1970, quando o movimento sindical, especialmente na América Latina, passa a reivindicar mudanças na atenção e promoção da saúde dos trabalhadores (Lourenço; Bertani, 2008).

Fruto de longa luta por parte dos movimentos sociais e sindicais, o reconhecimento formal desse vínculo e a legitimação da Saúde do Trabalhador pelo Estado ocorreram tardiamente no Brasil, apenas com a Constituição Federal de 1988, no âmbito da qual trabalho e saúde foram institucionalizados na forma de cidadania e direitos sociais, passando a saúde do trabalhador a integrar a política de saúde pública, um direito de todos e dever do Estado (Lourenço; Bertani, 2008, p. 174). Contudo, como afirmam Lourenço e Bertani, "os direitos sociais ampliados pela Constituição de 1988 tornam-se distantes do usufruto do conjunto dos trabalhadores".

Malgrado seja necessário reconhecer, assim como o faz Silveira (2009, p. 43), que "os trabalhadores compartilham com os não trabalhadores formas de adoecer e morrer que são decorrentes do estilo de vida, do sexo, da idade, do perfil genético e dos fatores de risco de natureza ambiental aos quais todos se expõem", não se pode deixar de notar os vínculos indeléveis entre a atividade laboral que exercem e os mais diversos tipos de agravos sofridos pelos trabalhadores no Brasil, país onde os agravos do trabalho ganham o vexatório estatuto de problema de saúde pública (Binder; Cordeiro, 2003). De modo análogo à destruição ambiental, podemos afirmar que a degradação do trabalho assume um caráter verdadeiramente sistêmico no país (Thomaz Júnior, 2017a).

Conforme dados da Previdência Social apresentados pelo Observatório Digital de Saúde e Segurança do Trabalho, ${ }^{5}$ entre 2012 e 2017 ocorreram cerca de 14,9 mil mortes em acidentes de trabalho no Brasil, num total de mais de 3,9 milhões de acidentes de trabalho registrados, perdendo-se 307 milhões de dias de trabalho. Nesse mesmo período, os gastos com benefícios acidentários já beiravam os $\mathrm{R} \$ 25$ bilhões. Portanto, não é de espantar que o Brasil seja considerado pela OIT como o quarto pior país do mundo em matéria de segurança e saúde do trabalho, atrás apenas da China, Índia e Indonésia. ${ }^{6}$ 
Esse panorama assustador representa, no entanto, apenas a ponta de um iceberg muito maior, devido a uma extensa série de problemas envolvendo a identificação, o registro e a própria compreensão sobre a causalidade dos agravos. A subnotificação massiva e generalizada ${ }^{7}$ é o mais conhecido, mas não o único dentre eles. Mesmo quando são reportados, os dados estatísticos são parciais ${ }^{8}$ e as informações são desconectadas, já que as fontes não se relacionam entre si e não cobrem a totalidade dos trabalhadores (Binder; Cordeiro, 2003; Waldvogel, 2011). Ademais, os trabalhadores encontram grande dificuldade para comprovar o vínculo entre as enfermidades de que padecem e a atividade de trabalho que exercem e falta vontade política por parte dos gestores responsáveis pelas ações de vigilância em saúde do trabalhador, sobretudo no nível municipal (Lourenço, 2011).

Não obstante, o mais grave dos engodos situa-se não no campo do registro e quantificação dos agravos, mas na interpretação que se faz sobre a maior parte deles. Os chamados "acidentes de trabalho", tal como são oficialmente nomeados os agravos pela Previdência Social, são fenômenos socialmente determinados (Binder; Cordeiro, 2003), envolvem uma multiplicidade de fatores e apresentam diferentes facetas (Vilela; Iguti; Almeida, 2004; Lourenço, 2011), sendo previsíveis na maioria das ocorrências ligadas ao processo produtivo (Pignati; Machado; Cabral, 2007). Ainda assim, segundo Vilela, Iguti e Almeida (2004), sua análise é sempre influenciada pela visão ou compreensão do analista, podendo-se:

[...] afirmar que predomina, no Brasil e no mundo, a compreensão de que acidente é um evento simples, com origem em uma ou poucas causas, encadeadas de modo linear e determinístico. Sua abordagem privilegia a ideia de que os acidentes decorrem de falhas dos operadores (ações ou omissões), de intervenções em que ocorre desrespeito à norma ou prescrição de segurança, enfim, 'atos inseguros' originados em aspectos psicológicos dos trabalhadores (Vilela; Iguti; Almeida, 2004, p. 571).

Deste modo, por meio do paradigma hegemônico, biológico, unicausal, de cunho comportamental, com realce para a visão empirista e positivista trazida da clínica que toma o trabalhador como paciente/ objeto da técnica e centrado na ideia absolutamente falaciosa de um indivíduo livre e consciente, transfere-se a culpa à vítima dos acidentes, numa completa inversão da realidade reforçada pelo preconceito de classe 
vigente e predominante em várias instituições e organizações no Brasil (Jackson Filho et al., 2013). A própria nomenclatura oficial parece reforçar algumas dessas premissas, uma vez que o termo "acidente" remete à ideia de um evento fortuito, imprevisto, inesperado. Daí decorre igualmente a crença infundada, porém enraizada e generalizada, de que o uso de Equipamentos de Proteção Individual (EPI) pelos trabalhadores aliado à adoção de regras rígidas de segurança pelas empresas são medidas eficazes para mitigar ou até mesmo eliminar o problema.

Esta perspectiva analítica, mais circunscrita às práticas tradicionais da Saúde Ocupacional, engendra-se sob o ponto de vista a-histórico e descontextualizado das relações econômicas, político-ideológicas e sociais que influenciam os nexos entre o trabalho e a determinação social do processo saúde-doença. Em decorrência, suas análises não compreendem o trabalho como categoria dialética e, por isso, acabam por conferir maior capacidade de controle do capital sobre os trabalhadores e trabalhadoras. Sua busca, portanto, não pode ser outra senão a da mera adequação técnica do ambiente de trabalho, do cumprimento de Normativas Regulamentadoras, da utilização dos EPI etc. Assim, a Saúde Ocupacional parte de uma ideia cartesiana do corpo como uma máquina que se expõe, inevitavelmente, a agentes/fatores de risco (físicos, químicos, biológicos, mecânicos) existentes no ambiente de trabalho (Lacaz, 2007).

Esses limites teórico-epistemológicos da Saúde Ocupacional estreitam o entendimento dos agravos à saúde dos trabalhadores no século XXI, pois sua causalidade é cada vez mais complexa e envolve as formas de organização do processo de trabalho e sua relação com a subjetividade dos trabalhadores. Por isso, é imprescindível imprimir um caráter histórico e multidisciplinar ao estudo das relações entre trabalho, saúde e agravos, para compreendê-las em sua dimensão social e relacionada às implicações da forma como se organizam os processos de trabalho nos mais distintos setores econômicos e lugares, sob a égide do capital. Outrossim, urge deixar claro que a degradação da saúde do trabalhador não se limita apenas ao agravo consumado (acidente, doença, lesão etc.), manifestando-se cotidianamente em diferentes graus de medo, ansiedade e insatisfação dentro e fora do local de trabalho, os quais, embora dificilmente possam ser mensurados, não deixam de ser reais e tampouco de afetar a vida dos trabalhadores. 
Diante do panorama brevemente esboçado neste item, estamos certos de que o campo da Saúde do Trabalhador representa um avanço para o entendimento da relação trabalho-saúde ao incorporar a dimensão da determinação social das doenças e reivindicar uma perspectiva histórica para a compreensão dos agravos à saúde dos trabalhadores. No entanto, sem negar tais avanços, compreendemos que uma abordagem territorial crítica, devidamente referenciada pelo método dialético-materialista, pode auxiliar sobremaneira os estudos em saúde do trabalhador e que, portanto, os geógrafos têm muito a dizer sobre esse assunto.

\section{Por um conceito dialético-materialista de território}

Território é um daqueles vocábulos presentes nos mais variados contextos (da ciência ao conhecimento popular, passando pela política e pelo planejamento de Estado), não unívoco e por vezes empregado com sentidos distintos e polissêmicos. Etimologicamente, sua origem está ligada a uma dupla significação: de um lado com terra e de outro com terror/aterrorizar, ou seja, tem a ver com dominação da terra e com inspiração do medo e do terror (Haesbaert, 2007). Historicamente, tem sido empregado tanto para se referir ao espaço de domínio de povos e sociedades humanas quanto de um determinado animal, grupo ou espécie.

Incorporado pelas ciências humanas, encontrou na Geografia seu campo de discussão mais sistemático, ganhando distinção de conceitochave, ou seja, de conceito capaz de sintetizar o ângulo a partir do qual essa disciplina examina a dimensão espacial da realidade (seu objeto primordial), ao lado do espaço geográfico (o mais amplo entre eles), da região, do lugar e da paisagem (Corrêa, 1995). Conquanto seu conteúdo semântico possa ter apresentado nuances em cada corrente e nas mais variadas escolas nacionais do pensamento geográfico, desde o século XIX o conceito de território confundia-se com a ideia de espaço de governança e soberania dos Estados nacionais modernos. E isso não por acaso, pois como demonstrou Lacoste (1988), como disciplina institucionalizada, a Geografia emergiu das promíscuas entranhas do imperialismo europeu, tornando-se, desde seus albores, um instrumento a serviço do Estado.

Semelhante redução sofreu o conceito de poder, componente fulcral do território, seja qual for a acepção. Como aduz Raffestin (1993), até a pouco o poder era sinônimo do poder institucionalizado do Estado, cuja 
expressão espacial é o território dos países. A partir das décadas de 1960 e 1970, entretanto, experimenta-se uma verdadeira revolução no plano do pensamento filosófico e da teoria social, engendrada, sobretudo, por novas e mais ricas leituras sobre o poder e pela valorização do espaço e do papel dos sujeitos sociais na construção da realidade.

De um lado, pensadores como Foucault (1988; 2002) passaram a argumentar em favor de uma concepção mais ampla de poder, aplicável também à compreensão de fenômenos desenrolados acima e abaixo do Estado, os quais suscitam resistência e são exercidos por intermédio de tecnologias e mecanismos produzidos historicamente, no âmbito das próprias relações sociais. De outro, expoentes do próprio marxismo, como Thompson (1998), colocaram em xeque o velho paradigma mecanicista e economicista, generalizante e redutor dos indivíduos a meros "dados da estrutura", confrontando-o com sujeitos vivos, situados, elementos ativos da história, portadores de identidade, experiências e subjetividade e ipso facto capazes de lutar e de transformar a realidade.

No bojo dessas transformações, renova-se igualmente o conceito de território a partir de uma perspectiva relacional e multiescalar do poder, inaugurando-se, assim, uma nova abordagem territorial dos fenômenos sociais que extrapola a Geografia para irrigar fertilmente outros domínios do conhecimento e da ação política. No terreno geográfico, esse conceito renovado conferiu fôlego à nascente Geografia Crítica brasileira de inspiração marxista, mostrando-se um instrumento indispensável na análise dos antagonismos e conflitos sociais, fato que praticamente coincide com os primeiros rudimentos de uma Geografia centrada no trabalho. ${ }^{9}$

Todavia, o espectro teórico, político e ideológico da inflexão em curso tem sido abrangente a ponto de contemplar, em seus extremos, desde os críticos mais contundentes do modelo de sociedade vigente, até teóricos reconhecidamente comprometidos com a manutenção da ordem burguesa e organismos supranacionais, passando por formuladores de políticas públicas em diversos níveis. Elevada ao paroxismo, a abordagem territorial tornou-se uma espécie de panaceia, fazendo proliferar leituras simplificadoras e redutoras da complexidade inerente à realidade e, mais precisamente, ao território (Souza, 2008). Em muitas análises, o território tem sido esvaziado de seu conteúdo mais característico e potencializador da crítica social radical e contundente, aparecendo ora como sinônimo de região, ora de meio ambiente ou simplesmente de recorte ou área. 
$\mathrm{Na}$ abordagem aqui defendida, o território é compreendido como fração do espaço geográfico, ${ }^{10}$ simultaneamente tomado do ponto de vista das e delimitado pelas relações de poder que caracterizam o intercâmbio metabólico dos homens entre si e com a natureza exterior por meio do trabalho (Mészáros, 2006). Sendo fração do espaço, o território é igualmente produto da sociedade e também a produz (Santos, 1988), constituindo-se por objetos e relações (de poder) que os animam e atuando, concomitantemente, como meio de produção e de controle (dominação), embora sirva para ocultar as relações reais e os conflitos existentes (Lefebvre, 1991).

Diferentes formas de intercâmbio metabólico consubstanciam territorialidades (ou seja, formas particulares de constituir e manter territórios) também diferentes e, por vezes, absolutamente antagônicas entre si, dando origem a uma situação de conflito insolúvel, pois em essência contraditória, dentro dos tacanhos limites da lógica capitalista. A partir deste entendimento, é possível conceber porque classes sociais e metabolismos distintos possuem diferentes e conflitantes territorialidades, produzem territórios contrapostos e se apropriam, utilizam e representam de formas diversas seus recursos (Perpetua, 2016a).

Para além da centralidade do trabalho e das relações de poder e, portanto, da tensão conflituosa permanente entre diferentes territorialidades, há ainda outros componentes importantes para pensar o conceito de território da maneira como temos procurado desenvolvê-lo:

(a) O caráter relacional. Mesmo não adotando o método dialéticomaterialista, a perspectiva relacional advogada por Raffestin (1993) encontra nele plena correspondência, na medida em que uma das características fundantes desse método é seu caráter relacional (Prado Júnior, 1973). O território é, pois, produto das relações de poder e todo território está em relação (sincrônica, diacrônica e geralmente conflituosa) com outros territórios.

(b) A multiescalaridade. As relações sociais definem os territórios, mas não o fazem numa única escala (a do Estado-nação, por exemplo) e, sim, em diferentes escalas superpostas umas em relação às outras, o que equivale a admitir que um território numa escala é sempre parte de outro território noutra escala. Se por sua ação, do Estado ao indivíduo, todo sujeito (individual ou coletivo) produz território, os territórios superpõem-se, muitas vezes não harmonicamente, segundo a abrangência 
das relações de poder. Vale lembrar que o jogo escalar é a maneira geográfica de apreender a totalidade, categoria central do método de Marx (Netto, 2011).

A multidimensionalidade. Ainda que se possa afirmar que o território é, essencialmente, um fato político, é um erro não considerá-lo, concomitantemente, como fato econômico, cultural etc. Como mediação do real (unidade do diverso e síntese de múltiplas determinações, diria Marx), o território é em si uma totalidade na qual se relacionam todos os complexos formadores da existência humana e social.

(d) A multiplicidade. Braudel (1992) dizia que, em sua vida cotidiana, os homens e as mulheres experimentam tempos e temporalidades múltiplos e contraditórios. O mesmo se pode dizer em relação aos territórios e territorialidades da vida cotidiana. Os princípios anteriormente explicitados conduzem à conclusão de que, invariavelmente, uma determinada porção do espaço será sempre constituída por múltiplos territórios e territorialidades.

(e) A processualidade. O tempo e a temporalidade representam também uma dimensão fundamental dos territórios, pois assim como possuem uma extensão, eles têm uma duração, não existindo território eternamente fixo e perene. Mesmo o território de "longa duração" de um Estado nacional, um dia foi fruto de um processo de territorialização, podendo mudar os seus limites em virtude de um amplo conjunto de fatores. Além do mais, o fato territorial demanda sempre uma visão processual para ser bem compreendido em seu fazer-se - desfazer-se - refazer-se, isto é, em seu movimento de territorialização - desterritorialização reterritorialização. Para Thomaz Júnior (2017b) esse movimento pode ser repensado para apreender a dinâmica do trabalho, portanto, enquanto movimento territorial do trabalho e, em nível teórico mais profundo, movimento territorial de classe.

Essa breve incursão conceitual teve o propósito de preparar o caminho para entendermos que a relação social, histórica e produtiva entre capital e trabalho, base dos agravos impostos aos trabalhadores, também se consubstancia por meio de uma determinada territorialidade, apoiando-se e produzindo um determinado tipo de território hegemonizado pelo capital em detrimento do trabalho. 
Os territórios da relação capital/trabalho: precarização e agravos à saúde dos trabalhadores

Como ponto de partida, a compreensão dos territórios da relação capital/trabalho requer o entendimento da dialética do trabalho, que culmina na teoria da alienação do trabalho em Marx. Dialética, porque assume o sentido de afirmação e negação, ao mesmo tempo, pois o trabalho, define Marx (2013, p. 255), "é, antes de tudo, um processo entre o homem e a natureza, processo este em que o homem, por sua própria ação, medeia, regula e controla seu metabolismo com a natureza”. É ainda “[...] a condição natural da existência humana, a condição, independente de todas as formas sociais de intercâmbio da matéria entre o homem e a natureza" (Marx, 2008, p. 62-63). Nessa condição de produtor de valores de uso para a satisfação das necessidades humanas legítimas, o trabalho concreto pode ser entendido como elemento humanizador e emancipatório por excelência.

Todavia, na sociedade capitalista o trabalho assume uma forma estranhada, aparecendo como trabalho abstrato, voltado para a produção de valores de troca cuja finalidade não é outra senão a extração de trabalho excedente (mais-valor) para a acumulação ampliada do capital (Marx, 2013). Mészáros (2006) assevera que disso resulta a alienação do trabalho, a "condição inconsciente da humanidade"11 instauradora da perda de controle por parte dos seres humanos em quatro aspectos essenciais e interligados de sua existência: em relação à natureza exterior; em relação à sua própria atividade produtiva; quanto ao seu ser genérico, portanto, em relação à consciência de sua espécie; e em relação aos outros seres humanos. Eis o fulcro da dominação do capital sobre o trabalho.

À luz da teoria, a dominação e a exploração capitalistas aparentam ser fatos claros como o dia. Na prática, entretanto, sua existência reveste-se de um denso véu mistificador que as invisibiliza e inverte, fazendo-as aparecer ante os próprios trabalhadores como condição máxima de igualdade e liberdade. Isso ocorre porque, diferentemente da realidade de outros regimes sociais (o escravismo e o feudalismo, por exemplo), em que a dominação era essencialmente política e, portanto, exterior aos indivíduos, sob a égide do capital ela se dá como que por meio de "fios invisíveis", na medida em que "a coerção muda, exercida pelas relações econômicas sela o domínio do capitalista sobre o trabalhador” (Marx, 2013, 
p. 808). Com efeito, tal "truque de mestre" só pode ser exitoso se, e na medida em que, a desigualdade substantiva entre as pessoas for revestida por uma igualdade formal (Mészáros, 2011).

Dominação e exploração do trabalhador, como quaisquer outros fenômenos sociais, possuem uma dimensão espacial passível de ser lida por meio da ótica das relações de poder e, portanto, da "lente" do território. O território onde se reproduz o capital, por meio da extração de trabalho não pago, é o território da dominação e da desrealização do trabalho, cujo corolário, no limite, é a degradação do sujeito que trabalha não como exceção, mas como tendência objetiva e relacionada à determinação social do processo saúde-doença ${ }^{12}$.

Laurell (1982) corrobora com esse argumento ao advogar a existência de uma estreita articulação entre o processo de trabalho e o processo saúde-doença, processo que assume características distintas a depender da forma de inserção de cada grupo/classe na produção, sendo determinado pelo modo como o homem se apropria da natureza num dado momento. E como esclarece Marx (2013, p. 342) acerca do processo de trabalho capitalista, "o capital não tem [...] a mínima consideração pela saúde e duração da vida do trabalhador, a menos que seja forçado pela sociedade a ter essa consideração", pois os ataques à saúde e ao bem-estar físico e psíquico dos trabalhadores são inerentes ao modo de ser do capital, posto que as leis da produção impõem-se aos capitalistas (ou aos seus gestores ad hoc) como leis coercitivas, férreas e externas à sua consciência.

Foucault foi um dos primeiros autores a identificar a dimensão espacial da dominação capitalista e teorizar sobre ela. Ao examinar a natureza das relações e dos mecanismos de poder, o filósofo francês sinalizou para o fato de que a ascensão histórica da burguesia significou também a ascensão de uma nova forma de poder, o "poder disciplinar", em contraposição ao "poder soberano" vigente até então. Enquanto este se assentava na terra e em seus produtos, aquele tinha por objeto os corpos e seus atos, em suma, o trabalho e sua potência. Em Vigiar e punir (1988), Foucault não limita o poder disciplinar apenas à produção capitalista, demonstrando como ele passa a estar presente nas diversas formas de dominação existentes em todo o corpo social, do manicômio à prisão, do hospital ao exército, passando pela fábrica, funcionando como uma espécie de fórmula modelar da dominação. Porém, adverte, “[...] é, numa boa proporção, como força de produção que o corpo é investido por relações 
de poder e de dominação [...]”, pois “o corpo só se torna força útil se é ao mesmo tempo corpo produtivo e corpo submisso"13.

O mesmo autor é categórico ao afirmar que a disciplina "procede em primeiro lugar à distribuição dos indivíduos no espaço" ${ }^{14}$ produzindo com isso um espaço disciplinar sobre o qual se apoia, antes de tudo, o exercício do poder. São princípios básicos desse espaço o cercamento, a localização imediata ou quadriculamento, a funcionalização, o alinhamento e a vigilância total e permanente.

Deste modo, é possível perceber que a relação capitalista de trabalho é, por definição, uma relação de poder marcada pela dominação da pessoa que trabalha por outrem, ou seja, pelo dirigente do processo de valorização. Ela se dá sobre e por meio de um substrato espacial moldado à sua imagem e semelhança e constitui um território específico: o local de trabalho, lócus da hegemonia do capital e, antes de qualquer outra coisa, um lugar de disputas, tensões e antagonismos de classe; um espaço onde se desdobram dominação e resistência, assumindo, esta última, formas implícitas ou explícitas, veladas ou declaradas; um território em que as personalidades individuais assumem, quase sempre inconscientemente, papéis sociais rígidos, transformando-se em personificações das relações sociais de produção.

Como indicam Barreto e Heloani (2013), quando um indivíduo entra em uma determinada organização do trabalho, ele encontra uma realidade pronta, materializada, com suas normas e regras implícitas e/ ou explícitas, bem como procedimentos que deve desenvolver e que $a$ ele se impõem. Isso equivale a dizer que, mesmo resistindo de diversas formas e permanentemente - pois toda dominação gera resistência -, o trabalhador passa a ser regido por uma territorialidade que lhe é estranha e contrária à sua vontade. No caso brasileiro isso é ainda mais evidente, pois o ambiente de trabalho costuma ser regido por relações hierárquicas rígidas e relações de trabalho essencialmente autoritárias (Vilela; Iguti; Almeida, 2004).

O território da relação capital/trabalho é composto pela interação permanente entre as condições materiais e as formas de organização e controle do trabalho. Conquanto não desenvolva uma abordagem propriamente territorial, Dejours (1992) reconhece tal relação de indissociabilidade entre as condições de trabalho e as relações de trabalho, correspondendo as primeiras ao conjunto formado pelos ambientes 
físico, químico, biológico e pelas condições de higiene, segurança e as características antropométricas do posto de trabalho, ao passo que as últimas dizem respeito à divisão do trabalho, ao conteúdo das tarefas, ao sistema hierárquico, às modalidades de comando, enfim, às relações de poder.

A territorialidade do capital, portanto, subordina o trabalhador, colocando-o em contato com os agentes de risco (físicos, químicos, ergonômicos, mecânicos, biológicos e organizacionais), os quais geralmente atuam de forma combinada e podem afetar diretamente ou indiretamente a saúde dos trabalhadores (Agostini, 2002). Sem contar os inúmeros fatores de sofrimento e o iminente risco de adoecimento mental desencadeado pela atividade laboral, tão bem delineado por Dejours (1992). Isso significa que a abordagem tradicional, pautada no meio ambiente de trabalho desequilibrado e no uso de soluções individualizadas e que dependam da performance do trabalhador, simplesmente não condiz com a realidade.

Não obstante, faz-se necessário observar, assim como as formas de organização da produção, as formas de controle (dominação) do trabalho mudam com o tempo e diferem no espaço, o que repercute diretamente nos tipos de agravos característicos de cada período e regime produtivo. No domínio da produção tipicamente taylorista-fordista, cujo zênite foi atingido na primeira metade do século XX, reinaram a fragmentação, a parcialização das tarefas, a divisão entre concepção e execução e a imposição de uma rígida hierarquia sobre os trabalhadores. Já sob a vigência do regime flexível, gestado no interior das transformações do capitalismo pós-1970, tornaram-se predominantes a polivalência e a multifuncionalidade dos trabalhadores, a gestão sistêmica e combinada do tipo toyotista, a reaproximação entre concepção e execução, o trabalho em "células" ou "ilhas" de produção, as exigências de envolvimento direto dos trabalhadores com o processo produtivo sob a batuta do autocontrole, e a brutal intensificação do ritmo de trabalho.

Marcada pela flexibilização (da jornada, dos contratos, da remuneração etc.) que conduziu à precarização extrema das relações de trabalho, a transição entre esses dois modelos alterou o próprio perfil dos riscos e agravos predominantes. Dos riscos físicos e químicos, de acidentes ligados a diversos tipos de lesões, como cortes e torções, e das intoxicações, passa-se a riscos muito mais sutis, subjetivos e invisibilizados, a exemplo do assédio moral (Braz, 2013; Barreto; Heloani, 2013). O resultado é a 
epidemia atual de casos de transtornos mentais e lesões por esforço repetitivo (LER/DORT).

Ressalve-se o fato de que o Brasil experimentou o regime flexível ou toyotista antes mesmo do modelo taylorista-fordista ter tido condições de se consolidar, mesclando-se, inclusive, relações de trabalho pré-capitalistas com o que há de mais moderno em termos de produção e gestão do trabalho (Braz, 2013). Destarte, amalgamam-se igualmente agravos característicos de cada período/modelo, às vezes no mesmo território e no mesmo setor produtivo (Silveira, 2009).

Por fim, convém esclarecer ao menos en passant que a abordagem territorial da saúde do trabalhador não deve limitar-se ao nível local, do espaço de trabalho em si, levando em conta igualmente as relações de poder desdobradas em outras escalas. Pois os mesmos princípios que fragmentam, hierarquizam e tornam os homens desiguais na sociedade capitalista estão presentes na produção capitalista do espaço, de maneira que o espaço capitalista é essencialmente fragmentado, polarizado, desigual e combinado (Smith, 1988; Brandão, 2007). Assim, compreender o que se passa em um processo de trabalho específico e geograficamente localizado, exige considerar contextos geográficos muito mais amplos, sobretudo em uma conjuntura de mundialização do capital, na qual processos produtivos particulares no mundo todo se encadeiam, afinados pelo diapasão da economia global financeirizada.

\section{Considerações finais}

Nosso objetivo, com este ensaio teórico-epistemológico, foi demonstrar a possibilidade de análise das questões referentes à saúde do trabalhador ressaltando sua dimensão espacial intrínseca, por meio de uma abordagem crítica de cariz dialético-materialista centrada no conceito de território. Procuramos evidenciar como a produção capitalista engendra formas de controle e dominação historicamente modificadas e projetadas espacialmente como territórios da hegemonia do capital sobre o trabalho, que se expressam nos mais distintos setores econômicos, no campo e na cidade.

Tal perspectiva permite considerar em conjunto tanto as condições de trabalho constitutivas do substrato espacial de todo local de trabalho como as formas de organização e controle do trabalho que com elas 
interagem continuamente, sob o imperativo insuprimível da acumulação ampliada do capital, que faz da imposição de situações de agravos à saúde dos trabalhadores uma condição objetiva inerente, e não algo fortuito ou residual. Condição, diga-se de passagem, elevada à enésima potência em um país de capitalismo dependente como é o caso do Brasil. Daí ser inconcebível limitar as perspectivas de análise - e propostas práticas para a solução de problemas que delas derivam - à Saúde Ocupacional, centrada no comportamento dos trabalhadores e/ou nos agentes de risco, como se tudo não passasse de uma questão de adequação e aperfeiçoamento. Daí, igualmente, a importância recobrada pela Saúde do Trabalhador como campo multidisciplinar capaz de referenciar perspectivas críticas avessas ao reformismo cuja finalidade última é assegurar a continuidade da reprodução ampliada do capital.

Por sua própria natureza autoexpansiva e incontrolável, a reprodução do capital é incompatível com a saúde e o bem-estar dos trabalhadores, do mesmo modo como não pode ser conciliada com a preservação da natureza. Isto é, desde a perspectiva aqui adotada e defendida, a degradação do trabalho deve ser vista como a regra e não a exceção, assumindo, cada vez mais, um caráter sistêmico (Thomaz Júnior, 2017a). Longe de ser apenas um pressuposto teórico, esperamos que esse seja também um princípio capaz de contribuir com a ação política daqueles que, em diferentes espaços, lutam pelos direitos fundamentais dos trabalhadores.

\section{Notas}

1 Ver, entre outros, Soja (1993) e Smith (2000).

2 A esse respeito, ver, por exemplo, os trabalhos de Bezerra (2012), Heck (2017), Perpetua (2016a) e Thomaz Júnior (2017a). Para um diálogo entre a Geografia do Trabalho e outras áreas dos estudos do trabalho, ver Perpetua (2016b).

3 Segundo dados apresentados pela Organização Internacional do Trabalho (OIT, 2017), a cada ano, 2,3 milhões de pessoas morrem e cerca de 300 milhões ficam feridas devido a acidentes e enfermidades relacionadas com o trabalho. Isso significa que a cada 5 minutos, 5 trabalhadores são mortos e 3 mil acidentes ocorrem. Mensurados em termos econômicos, os acidentes custam algo em torno de $4 \%$ do PIB mundial em dias de trabalho perdidos, gastos com saúde, pensões, reabilitação e reintegração. A própria agência, no entanto, reconhece que os dados estão longe de refletir a magnitude real do problema, porquanto a maior parte dos casos de acidentes e adoecimentos não é reportada. Disponível em: <https://news.un.org/pt/audio/2017/04/1203771-acidentesde-trabalho-matam-23-milhoes-de-pessoas-por-ano>. Acesso em: 20 jan. 2017. 
5 Disponível em: <https://observatoriosst.mpt.mp.br/>. Acesso em: 10 jan. 2018.

6 Disponível em: <http://agenciabrasil.ebc.com.br/geral/noticia/2016-04/brasil-e-quartodo-mundo-em-acidentes-de-trabalho-alertam-juizes>. Acesso em: 10 jan. 2018.

7 Com base na literatura disponível sobre o tema, Pignati e Machado (2005) estimam que a subnotificação dos dados da Previdência Social atinge $80 \%$. Para o caso das intoxicações por agrotóxicos registradas pelo Sistema Nacional de Agravos de Notificação (SINAN/ SUS), os especialistas admitem a existência de 50 casos não registrados para cada caso registrado (Rodrigues, 2012).

8 Os dados da Previdência Social, por exemplo, cobrem apenas os trabalhadores formais, deixando de fora parte significativa da PEA.

9 Dois textos seminais sobre o assunto foram apresentados por Moreira (2002) e Thomaz Júnior (2002). Alguns anos antes, em 1996, este último já havia criado o Centro de Estudos de Geografia do Trabalho (CEGeT), sediado na UNESP - Campus de Presidente Prudente-SP.

10 Com essa definição contrapomo-nos, de uma só vez, às teses de que o território é posterior ao espaço (Raffestin, 1993) e de que o território é composto apenas pelas relações de poder, e não pelo substrato espacial que as comporta. Quanto à segunda assertiva, é necessário admitir que mesmo que as formas do substrato espacial não mudem quando outra territorialidade delas se apropria, muda-se necessariamente seu conteúdo.

11 (Raffestin, 1993, p. 99).

12 Este fato tem sido evidenciado empiricamente por diversos estudos desenvolvidos no âmbito da Geografia do Trabalho, em diferentes recortes geográficos e setores de atividade, a exemplo dos trabalhos de Mendonça (2004), sobre as questões vinculadas à produção de cultivos de exportação com destaque para a soja; Barreto (2012) e Thomaz Júnior (2002, 2009, 2017b), acerca da produção de açúcar e álcool; Bezerra (2012), a respeito da fruticultura; Heck (2017), sobre o setor de abate de suínos e aves; Perpetua (2016a, 2016b), quanto à produção de celulose, entre outros.

13 Foucault, 1998, p. 28.

14 Foucault, 1998, p. 130.

Financiamento

Este texto é produto das atividades de pesquisa realizadas no âmbito de dois Projetos de Pesquisa financiados pelo CNPq: 1) "Expansão Territorial do Agrohidronegócio e os Impactos para o Trabalho e Movimentos Sociais no Século XXI". Chamada: UNIVERSAL (Processo: 458711/2014-4). 2) "Movimento Territorial de Classe, Plasticidade do Trabalho e os Impactos na Saúde do Trabalhador no Século XXI (conflitos territoriais e luta pelo acesso à terra e à água)”. Chamada: PQ-1/CNPq (Processo: 304514/2015-2), e de um Projeto, financiado pela FAPESP: 3) 
"Mapeamento e análise do território do agrohidronegócio canavieiro no Pontal do Paranapanema - São Paulo - Brasil: Relações de trabalho, conflitos, formas de uso da terra e da água, e a saúde ambiental”. Projeto Temático/FAPESP (Processo: 2012/23959-9). Vigência: 01/08/2013 a $31 / 07 / 2018$.

\section{Referências}

AGOSTINI, M. Saúde do trabalhador. In: ANDRADE, A.; PINTO, S. C.; OLIVEIRA, R. S. Animais de laboratório: criação e experimentação. Rio de Janeiro: Editora Fiocruz, 2002. [on-line].

BARRETO, M. J. Territorialização das agroindústrias canavieiras no Pontal do Paranapanema e os desdobramentos para o trabalho. 2012. 245 f. Dissertação (Mestrado em Geografia) - Faculdade de Ciências e Tecnologia, Universidade Estadual Paulista, Presidente Prudente, São Paulo, 2012.

BARRETO, M.; HELOANI, R. Assédio laboral e as questões contemporâneas à saúde do trabalhador. In: NAVARRO, V. L.; LOURENÇO, E. A. de S. Avesso do trabalho III: Saúde do trabalhador e questões contemporâneas. São Paulo: Outras Expressões, 2013. p. 107-124.

BEZERRA, J. E. A fruticultura no Nordeste Semiárido: internacionalização, conflitos territoriais e a precarização do trabalho. 2012. Tese (Doutorado em Geografia) - Faculdade de Ciências e Tecnologia, Universidade Estadual Paulista, Presidente Prudente, São Paulo, 2012.

BINDER, M. C. P.; CORDEIRO, R. Sub-registro de acidentes de trabalho em localidades do estado de São Paulo. Rev. Saúde Pública, v. 4, n. 37, p. 409-416, 2003.

BRAZ, V. A. G. A. O trabalhador entre a saúde e a (in)segurança do trabalho. Rev. Em Pauta, Rio de Janeiro, v. 11, n. 32, p. 273-295, 2013.

BRANDÃO, C.A. Território e desenvolvimento: as múltiplas escalas entre o local e o global. Campinas: Unicamp,2007.

BRAUDEL, F. Escritos sobre a História. São Paulo: Perspectiva, 1992.

CORRÊA, R. L. Espaço, um conceito-chave da Geografia. In: CASTRO, I. E. de; GOMES, P. C. da C.; CORREAA, R. L. (Org.). Geografia: Conceitos e Temas. Rio de Janeiro: Bertrand Brasil, 1995.

DEJOURS, C. A loucura do trabalho: estudo de psicopatologia do trabalho. São Paulo: Cortez-Oboré, 1992.

FOUCAULT, M. Microfísica do poder. Rio de Janeiro: Graal, 2002.

. Vigiar e punir: o nascimento da prisão. Petrópolis, RJ: Vozes, 1988.

HAESBAERT, R. Território e multiterritorialidade: um debate. Geographia, Niterói, Rio de Janeiro, ano IX, n. 17, p. 19-46, 2007. 
HECK, F. M. No abate de frangos e suínos: o descarte do trabalho. Curitiba: Prismas, 2017.

JACKSON FILHO, J. M. et al. Sobre a "aceitabilidade social” dos acidentes de trabalho e o inaceitável conceito de ato inseguro. Rev. Bras. Saúde Ocup., São Paulo, v. 38, n. 127, p. 6-8, 2013.

LACAZ, F. O campo Saúde do Trabalhador: resgatando conhecimentos e práticas sobre as relações trabalho-saúde. Cad. Saúde Pública, Rio de Janeiro, v. 23, n. 4, p. 757-766, abr. 2007.

LACOSTE, Y. A Geografia: isso serve, em primeiro lugar, para fazer a guerra. São Paulo: Papirus, 1988.

LAURELL, A. C. A saúde-doença como processo social (La salud-enfermidad como proceso social). Revista Latinoamericana de Salud, Mexico, n. 2, p. 7-25, 1982.

LEFEBVRE, H. The production of space. London: Blackwell Publishing, 1991.

LOURENÇO, E. A. de S. Agravos à saúde dos trabalhadores no Brasil: alguns nós críticos. Revista Pegada, v. 12, n. 1, p. 3-33, jan. 2011.

. O mundo do trabalho adoece. Revista da RET, ano II, n. 3, p. 1-36, 2008.

LOURENÇO, E. A. de S.; BERTANI, I. F. Saúde do trabalhador em pauta. Serviço Social \& Realidade, Franca, São Paulo, v. 17, n. 2, p. 172-201, 2008.

MARX, K. Contribuições à crítica da economia política. [1859]. São Paulo: Expressão Popular, 2008.

. O capital: crítica da economia política. São Paulo: Boitempo, 2013. (Livro I - processo de produção do capital).

MENDES, R.; WAISSANN, W. Aspectos Históricos da Patologia do Trabalho. In: Patologia do trabalho: atualizada e ampliada. Rio de Janeiro: Atheneu, 2005.

MENDONÇA, M. R. A urdidura espacial do capital e do trabalho no Cerrado do Sudeste Goiano. 2004. 458 f. Tese (Doutorado em Geografia) - Faculdade de Ciências e Tecnologia, Universidade Estadual Paulista, Presidente Prudente, São Paulo, 2004.

MÉSZÁROS, I. A teoria da alienação em Marx. São Paulo: Boitempo, 2006.

Boitempo, 2011.

Para além do capital: rumo a uma teoria da transição. São Paulo:

MINAYO-GOMEZ, C.; THEDIM-COSTA, S. M. da F. A construção do campo da saúde do trabalhador: percurso e dilemas. Caderno de Saúde Pública, Rio de Janeiro, n. 13 (Suplemento 2), p. 21-32, 1997.

MOREIRA, R. Para onde vai o pensamento geográfico? Por uma epistemologia crítica. São Paulo: Contexto, 2009.

. Teses para uma Geografia do Trabalho. Revista Ciência Geográfica, Bauru, São Paulo, ano VIII, v. 11, n. 22, 2002. 
NETTO, J. P. Introdução ao estudo do método de Marx. São Paulo: Expressão Popular, 2011.

PERPETUA, G. M. Encruzilhadas teórico-político-metodológicas nos estudos do trabalho: um diálogo entre a Sociologia do Trabalho, a História Social do Trabalho e a Geografia do Trabalho. Pegada, Presidente Prudente, São Paulo, v. 17, n. 1, p. 28-46, 2016 b.

- Pilhagem territorial, precarização do trabalho e degradação do sujeito que trabalha: a territorialização do capital arbóreo-celulósico no Brasil contemporâneo. 2016a. 370 f. Tese (Doutorado em Geografia) - Faculdade de Ciências e Tecnologia, Universidade Estadual Paulista, Presidente Prudente, São Paulo, 2016a.

PIGNATI, W. A.; MACHADO, J. M. H. Riscos e agravos à saúde e à vida dos trabalhadores das indústrias madeireiras de Mato Grosso. Ciência \& Saúde Coletiva, Rio de Janeiro, v. 10, n. 4, p. 961-973, 2005.

PIGNATI, W. A.; MACHADO, J. M. H.; CABRAL, J. F. Acidente rural ampliado: o caso das "chuvas" de agrotóxicos sobre a cidade de Lucas do Rio Verde-MT. Ciência e Saúde Coletiva, Rio de Janeiro, v. 12, n. 1, p. 105-114, 2007.

PRADO JÚNIOR, C. Teoria marxista do conhecimento e método dialético materialista. Discurso: Revista do Departamento de Filosofia da Faculdade de Filosofia, Letras e Ciências Humanas da Universidade de São Paulo, São Paulo, ano IV, n. 4, p. 41-78, 1973.

RAFFESTIN, C. Por uma geografia do poder. São Paulo: Ática, 1993.

RODRIGUES, C. L. Agrotóxicos: saúde e segurança dos trabalhadores rurais, aspectos preventivos e controle de riscos, perspectivas jurídicas e extrajurídicas. 2012. 137 f. Monografia (Especialização em Direito Material e Processual do Trabalho) - Faculdade de Direito da Universidade de São Paulo, Universidade de São Paulo, São Paulo, 2012.

SANTOS, M. O espaço geográfico como categoria filosófica. Terra Livre, São Paulo, n. 5, 1988.

SILVEIRA, M. Saúde do trabalhador. Belo Horizonte: Nescon; UFMG; Coopmed, 2009.

SMITH, N. Contornos de uma política espacializada: veículo dos sem teto e a construção da escala geográfica. In: ARANTES, A. (Org.). O espaço da diferença. Campinas, SP: Papirus, 2000.

. Desenvolvimento desigual. Rio de Janeiro: Bertrand, 1988.

SOJA, E. W. Geografias pós-modernas: a reinserção do espaço na teoria social crítica. Rio de Janeiro: Jorge Zahar Editor, 1993.

SOUZA, M. L. de. "Território" da divergência e da confusão: em torno das imprecisas fronteiras de um conceito fundamental. In: SAQUET, M. A.; SPOSITO, E. S. (Org.). Territórios e territorialidades: teorias, processos e conflitos. São Paulo: Expressão Popular, 2009. p. 57-72. 
THOMAZ JÚNIOR, A. Degradação sistêmica do trabalho no agrohidronegócio. Mercator, Fortaleza, v. 16, p. 1-20, 2017a.

. Dinâmica geográfica do trabalho no século XXI: Limites explicativos, Autocrítica e Desafios teóricos. 2009. 985 f. Tese (Livre Docência em Geografia do Trabalho) - Faculdade de Ciências e Tecnologia, Universidade Estadual Paulista, Presidente Prudente, São Paulo, 2009.

. Movimento territorial do trabalho e da classe trabalhadora, desterreação e os sujeitos transcendentes/da resistência no século XXI. 2017b. 303f. Tese (Professor Titular) - Faculdade de Ciências e Tecnologia, Universidade Estadual Paulista, Presidente Prudente, São Paulo, 2017b.

. Por uma Geografia do trabalho. Revista Pegada, Presidente Prudente, São Paulo, v. 3, n. Especial, p. 04-17, ago. 2002.

THOMPSON, E. P. Costumes em comum. São Paulo: Cia das Letras, 1998.

VAZ, D. dos S.; REMOALDO, P. C. A. A geografia da saúde brasileira e portuguesa: algumas considerações conceptuais. GEOUSP - Espaço e Tempo, São Paulo, n. 30, p. 173-191, 2011.

VILELA, A. G.; IGUTI, A. M.; ALMEIDA, I. M. Culpa da vítima: um modelo para perpetuar a impunidade nos acidentes de trabalho. Cad. Saúde Pública, Rio de Janeiro, v. 20, n. 2, p. 570-579, mar./abr. 2004.

WALDVOGEL, B. C. Quantos acidentes do trabalho ocorrem no Brasil? Proposta de integração de registros administrativos. In: MINAYO-GOMEZ, C.; MACHADO, J. M. H.; PENA, P. G. L. Saúde do Trabalhador na sociedade brasileira contemporânea. Rio de Janeiro: FIOCRUZ, 2011. p. 226-244.

Guilherme Marini Perpetua - Graduado em Geografia pela Universidade Estadual Paulista, mestre em Geografia pela Universidade Federal da Grande Dourados e doutor em Geografia pela Universidade Estadual Paulista. Atualmente, é professor colaborador e pós-doutorando na mesma universidade, campus de Presidente Prudente com bolsa da FAPESP. ORCID: https://orcid.org/0000-0002-0536-831X.

Fernando Mendonça Heck - Graduado em Geografia pela Universidade Estadual do Oeste do Paraná, mestre e doutor em Geografia pela Universidade Estadual Paulista. Atualmente, é professor no Instituto Federal de São Paulo, campus avançado de Tupã. ORCID: https://orcid.org/0000-0003-2209-8363.

Antonio Thomaz Junior - Graduação em Geografia pela Universidade Estadual Paulista, mestre e doutor em Geografia pela Universidade de São Paulo. Atualmente, é professor titular da Universidade Estadual Paulista, Campus de Presidente Prudente. ORCID: https://orcid.org/0000-0002-1015-2257. 
Contribuições dos autores

Todos os autores ofereceram substanciais contribuições científicas e intelectuais ao estudo. As tarefas de concepção e design do estudo, preparação e redação do manuscrito, bem como, revisão crítica, foram desenvolvidas em grupo. O autor Guilherme Marini Perpetua ficou especialmente responsável pelo desenvolvimento teórico-conceitual inicial; o segundo autor, Fernando Mendonça Heck, bem como o terceiro, Antonio Thomaz Junior, fizeram acréscimos e correções fundamentais a partir de suas experiências de pesquisa. O texto final expressa um trabalho coletivo realizado ao longo de anos de convivência e discussão entre os autores. 